\title{
Abstracts from the CHLA / ABSC 2004 Conference - On the Edge
}

\author{
St. John's, Newfoundland and Labrador, 14-18 May 2004
}

\section{Opening keynote: Health services and the need for information - Sister Elizabeth Davis}

Sister Elizabeth Davis fulfilled the duties of President and Chief Executive Officer with the Health Care Corporation of St. John's (HCCSJ) from 1994 to 2000. It was in her role as head of the HCCSJ that Sister Davis helped oversee a major reorganization of the health care system in Newfoundland and Labrador. During her time with the HCCSJ, a number of services were integrated, and the corporation was a partner in creating the Newfoundland and Labrador Centre for Health Information and the Newfoundland and Labrador Centre for Applied Health Research. Prior to her service with the HCCSJ, Sister Elizabeth was the executive director of St. Clare's Mercy Hospital and a high school teacher. She served as one of three commissioners on the 2003 Royal Commission on Renewing and Strengthening Newfoundland and Labrador's Place in Canada.

She holds a B.A. and B.Ed. from Memorial University of Newfoundland, an M.A. (Theology) from the University of Notre Dame, and an M.H.Sc (Administration) from the University of Toronto. She was also recently honoured with an honorary Doctor of Laws from Memorial University of Newfoundland. Sister Elizabeth is currently a doctoral student at the Toronto School of Theology, University of Toronto.

Sister Elizabeth has been a member of many boards and is currently a member of the Medical Council of Canada, the National Board of Medical Examiners of the United States, the Canadian Health Services Research Foundation, the Editorial Advisory Board of Hospital Quarterly, and the Advisory Committee on Advocacy for the Catholic Health Association of Canada. She has spoken provincially, nationally, and internationally on transforming the health care system, on maintaining a values base in times of uncertainty, on ethics in this new time, and on leadership today.

\section{Panel discussion I: Changing patterns in information dissemination - the SARS example}

Join our panel of health professionals, librarians, and the media in this discussion about the health information needs experienced during the severe acute respiratory syndrome (SARS) outbreak. Were there "special" needs that could or could not be met? What role do health libraries and health librarians play in satisfying those needs? What can the experience of the SARS crisis tell us about health information needs?

\section{Panel members}

Vivien Ludwin, Bracken Library, Queen's University (moderator)

Dr. Jim Hutchinson, Medical Director of Infection Control, Health Care Corporation of St. John's

Dr. David Allison, Medical Officer of Health, St. John's Region

Monica Kidd, CBC Radio

Elizabeth Uleryk, Hospital Library, The Hospital for Sick Children, Toronto

Bruce Gardham, Toronto Public Health Library

\section{Panel discussion Il: Salon A - Subscription agents in the digital age}

Join our panel of subscription agency representatives, librarians, and publishers as they examine the role of subscription agents in the era of the electronic journal. What role is there for subscription agents? Will they survive the switch to electronic media, or are they obsolete? This discussion should help libraries clarify what subscription agents can or cannot do in this period of change.

\section{Panel members}

Patrick Ellis, W.K. Kellogg Health Sciences Library, Dalhousie University (moderator)

John Lumsden, Ebsco Canada Ltd.

Georges Sarazin, Swets Information Services

Elizabeth Sutherland, W.K. Kellogg Health Sciences Library, Dalhousie University

\section{Contributed papers concurrent sessions Session 1: Changing structures}

1.1 Innovations and controversies in scholarly communication - Anne Smithers, Queen's University

Digital technologies and the Internet are having a dramatic and profound impact on scholarly communication and 
control of access to information. Traditional print resources, primarily serials, are increasingly being digitized and are enthusiastically embraced by information consumers. Despite the premise of reduced production and distribution costs for the online versions, escalating serials prices, which libraries have been facing for many years, are a continuing problem. Desktop access to full-text information resources leads health care administrators, health care professionals, and students to assume that all information is available at no cost and do not require library services. There is little recognition that libraries often face a "permission crisis", whereby limits are placed on how libraries and information consumers may use these electronic resources. New initiatives, many of which advocate "open access" to scholarly scientific information, are developing in response to both the pricing and permission crises. Electronic resources, whether fee-based or free, are raising new issues for libraries and publishers that must be resolved.

Health sciences librarians must keep abreast of the changing information environment and the variety of different strategies that are being employed to address the growing demand for timely, convenient, fair, and equitable access to information. This ever-changing information environment provides ample opportunity for health sciences librarians in all settings to take a leadership role in promoting the innovations and resolving the controversies in scholarly communication.

\subsection{Using technology to leverage journal content at the Canadian Medical Association - Deborah Scott- Douglas, Information Services, Canadian Medical Association}

\section{Introduction}

In the spring of 2003, the Information Services (IS) unit of the Canadian Medical Association created a site on the corporate intranet to which it migrated its network-based catalogue and other e-resources using DBText WebPublisher. The project provided an opportunity to exploit Web-based capabilities to overhaul a costly and inefficient — but highly valued - paper-based journal routing service.

\section{Program description}

Tables of contents for new journals are scanned, then "pushed" to clients based on predefined user profiles. Accompanying the image is a link to the full text for the issue of the journal, if available electronically. Complementing the e-mail-based Table of Contents service are Table of Contents and eJournals pages on the IS intranet site. The Table of Contents page facilitates general browsing of the newest issue of all journals in the collection, and the eJournal section provides access to the full text of journals to which the library subscribes.

\section{Outcomes}

The Table of Contents and eJournal services have become a cornerstone of the IS intranet site. Clients appreciate the easy access, the ability to customize, and the fact that it is delivered to their desktops. In addition, the services can now be extended to offsite clients previously excluded from the routing service. From an economic perspective, duplicate subscriptions have been eliminated, significantly reducing costs while maximizing access to, and usage of, journal contents. Journals are better managed and controlled, and there is significant improvement in staff efficiency. The new service has raised the profile of the IS unit across the organization and illustrates the leadership role that librarians can play in delivering relevant and timely information products tailored to the needs and interests of their clients.

\section{Discussion}

What were the technical challenges in building the system, and what are the ongoing management issues? What are the issues surrounding the integration of electronic and paper-based journals into a coherent collection? What was the reaction of clients to giving up their routing service, and how were they persuaded to try the new e-based service? How was the service marketed and promoted?

\subsection{Chasing the sun: a virtual reference project} between SAHSLC (SA) and SWICE (UK) - Susan Rockliff, Queen Elizabeth Hospital Library, Woodville, South Australia

In 2002, a discussion in the United Kingdom (UK) between South West Information for Clinical Effectiveness (SWICE) librarians (UK) and a member of the South Australian Department of Human Services Libraries' Consortium (SAHSLC) raised the possibility of developing an after-hours virtual reference service between the two consortium groups. The aim of the service is to put medical practitioners in contact with a librarian when urgent help is required in finding clinical medical information after hours. A trial project has begun and has been given the name "Chasing the Sun". The service will make use of time zone differences between the UK and Australia so that librarians at work in another country will be able to answer urgent patient-related queries that cannot wait until normal office hours. This talk looks at the development of "Chasing the Sun", from initial concept, funding proposal and trial project stage, to implementation. It includes details of the groundwork, software evaluation, trials, outcomes, cost and benefits, future directions, and potential problems yet to be experienced or overcome. This service is the first of its kind between health libraries in the world and offers potential for future worldwide expansion.

\section{Session 2: Challenges to access I}

2.1 From the library to the community: communitybased organizations as intermediaries for health information - Tiffany Veinot, Information Services, Canadian AIDS Treatment Information Exchange (CATIE), Toronto

\section{Introduction}

Health Canada's HIV/AIDS Treatment Information Environmental Scan (2000) found significant barriers for community-based AIDS service organizations (ASOs) accessing treatment information in Canada, while at the same time demonstrating the desire of people living with HIV/AIDS (PHAs) to obtain information face-to-face and 
from local sources such as ASOs. The following are some of the problems identified:

(i) Small organizations often lack awareness of treatment resources that are readily available

(ii) Larger organizations are often overwhelmed by the amount of information available

(iii) Information overload makes it difficult for ASOs to know whether they are providing the best or most current information.

\section{Methods}

In response to gaps described in the study, CATIE conducted a study to assess the needs and preferences of ASOs for national library services. CATIE conducted 64 telephone surveys with ASOs in Canada in 2001-2002. Respondents from all regions of Canada completed the survey.

\section{Results}

All of the organizations contacted indicated a need for library services and most indicated a need for multiple types of services. The most-needed services (with at least $40 \%$ of ASOs indicating a need) were document delivery, e-mail/mailing list, Web-based library services, and research and reference services. However, the least-needed service was a circulating collection of treatment information documents (27\%). Respondents also indicated a desire for multiple methods of accessing library services: 39\% preferred Web site access, 30\% preferred 1-800 telephone service access, and 23\% preferred e-mail access. The leastdesired ways to access services were from their local health library $(6 \%)$ or through in-person visits $(2 \%)$.

\section{Discussion}

ASOs are important providers of treatment information to PHAs in Canada. ASOs have a clear need for library services about HIV/AIDS treatment. There is a preference amongst ASOs for accessing library services via the Web and e-mail, with a corresponding lack of desire to physically travel to obtain resources. These findings may have relevance when designing health information services for community-based organizations for HIV/AIDS and other sectors.

2.2 Challenges to accessing health information: how the Canadian Health Network is structuring itself to facilitate access to all users - Sally Press and Christine Chang, Canadian Health Network

The Canadian Health Network $(\mathrm{CHN})$ is a national, bilingual, Web-based health information service, comprising a comprehensive network of over 900 Canadian non-profit health information providers with a primary focus on health promotion and disease and injury prevention. Specific organizations (affiliates) select and evaluate resources to be added to the centralized Web site.

Technology is one of the basic ingredients of public access to health information, and the $\mathrm{CHN}$ offers public access to health information by enabling e-health content. However, there is scope to enhance this experience and to minimize the inequalities in access to information. Even if users have access to the electronic health sites, they will only find what they are looking for if they know how to search for it and if the search process is facilitated by providing the appropriate tools.

A working group has been set up within the CHN structure to look at the issue of controlled vocabulary and the different uses of terminology and to evaluate the means of resolving it. This includes the possibility of developing a tool (thesaurus) that reflects the terminology used by the public and bridges the varying usage of terms found among the different areas that make up public health. This session will examine health literacy, the issue of controlled vocabulary in the CHN electronic setting, the steps involved in developing a tool to solve the problems encountered, the resources available to do so, the challenges faced along the way, and the outcomes expected.

\section{Invited speakers}

Boomers and generations $\mathrm{X} / \mathrm{Y}$ : redeveloping the library workforce - Susan Cleyle, Queen Elizabeth II Library, Memorial University of Newfoundland

Sue will discuss the many issues involved in regenerating library staff as we move into the period of retirement for the baby boomers. How does a library go about ensuring that it has the skilled and motivated staff available that are essential to providing quality services? How does a small library address these issues compared to a large library? Join Sue for an open discussion about this increasingly important issue.

The catalogue as master file - Louise White and Lisa Goddard, Queen Elizabeth II Library, Memorial University of Newfoundland

Lisa and Louise will discuss the issue of integrating the library catalogue with the wider library Web site. Most libraries maintain both a Web site and an online catalogue. In many cases, we find ourselves reproducing cataloguing information on the Web site to provide multiple access points for users. Links to electronic resources like e-journals, indexes, government information, and authoritative Web sites change often and can quickly become unmanageable when duplicated across multiple areas. The presentation will outline one academic library system's project to create custom Web interfaces that are automatically updated when the changes are made to the cataloguing record. These interfaces maintain the supremacy of the cataloguing record as a centralized authority but allow the library to create finding resources that are extremely customized to user needs.

\section{Humour is still the best medicine - Dr. Bill Eaton, Faculty of Medicine, Memorial University of Newfoundland \\ Dr. Eaton will speak of the sociology, anthropology, his- tory, and classification of humour, as well as the psycho- neuro-physiology of the laughter response!}

\section{Session 3: People issues and instruction}

3.1 Ontario hospital library managers' attitudes toward volunteers - Mary McDiarmid and Ethel Auster, University of Toronto

This presentation examines key issues identified in our research, funded by the Canadian Health Libraries Association, regarding the attitudes of Ontario hospital library 
managers toward the use of volunteers in hospital libraries. Between 23 March and 15 May 2003, 89 library managers in Ontario hospital libraries were sent a mail survey questionnaire. The findings showed that a majority of managers did not believe their libraries were adequately staffed with paid employees. Volunteers were more likely to be used by managers who did not believe their libraries were adequately staffed. Our discussion focuses on the extent of volunteer use and describes the activities that volunteers perform, the attitudes of Ontario hospital library managers toward volunteers, and the reasons for not using volunteers. The implications of volunteer use on library staff time, budget, staff relations, and public image are presented.

\subsection{Impact of librarians in first-year medical student problem-based learning (PBL) groups: a randomized controlled trial - Denise Koufogiannakis and Jeanette Buckingham, John W. Scott Health Sciences Library; David Rayner, Department of Laboratory Medicine and Pathology, University of Alberta}

\section{Introduction}

In a pilot project in 2002, librarians were introduced into the PBL groups during the introductory course for all MD and DDS students at the University of Alberta. Librarians worked with group facilitators to help guide the students in their selection of information resources for PBL cases and to help build the students' critical understanding of the clinical literature. Anecdotal evidence, from both faculty and students, suggests that the librarians' contribution was positive and much valued. The purpose of this 2003 study was to determine whether having a librarian present in the small groups improved understanding of evidence-based medicine concepts, understanding of the medical literature, and information access skills.

\section{Methods}

A controlled trial methodology was used, with librarians being randomized to the student groups. 164 first-year medical and dental students participated in the study. The course lasted 6 weeks, with data being gathered from a pre-test, post-test, and final exam questions.

\section{Results and discussion}

Results will show whether there is any benefit to the timeconsuming involvement of librarians in small-group learning or whether large group lecture, hands-on computer lab work and assignments are sufficient. Quiz and exam results will compare scores of the intervention groups (students with librarian) to the control groups (students without librarian). This research project used objective measures to determine whether there is any value added by including librarians at the small-group level.

\subsection{No time for MEDLINE - Susan Fahey, Health Sciences Library, Memorial University of Newfoundland, and Tamara Rader, BMJ Publishing Group, London, UK}

\section{Introduction}

The focus of medical publishing is shifting from primary research results (information) to critically appraised summa- ries of research evidence (knowledge). Publishers and associations have begun presenting the evidence in a clinical context through guidelines, summaries, health technology assessments, and decision support tools. As the awareness of and need for evidence in practice increases, new products and services are being created and marketed to our users to address this issue. These products have the potential to save physicians time and frustration when searching for the best evidence and making clinical decisions. Is MEDLINE the best tool to find this evidence? Is teaching MEDLINE search skills the best use of our time as instruction librarians?

\section{Objectives}

Our objective is to discover whether current practice in library instruction has adapted to the changing medical publishing world.

\section{Methods}

Literature review and e-mail survey of instruction librarians was used.

\section{Results}

We will present the results of our instruction librarian survey and discuss the variation in instructional programs (philosophies?) across settings. We will outline the benefits and limitations of teaching MEDLINE search skills and give an overview of innovative, critically appraised publications and databases.

\section{Discussion}

If current instruction practice is not accurately reflecting the availability of innovative products and services, why? Strategies to overcome barriers and adapt instructional programs will be discussed. Librarians can encourage physicians to incorporate emerging products and services into their searching strategies by adapting the content of their instruction programs to reflect current trends in medical publishing.

\section{Session 4: Instruction}

4.1 Developing information literacy skills in nursing and rehabilitation therapy students - Paola Durando and Patricia Oakley, Bracken Health Sciences Library, Queen's University

The environment in which nurses and rehabilitation therapists practice their professions is rapidly changing, resulting in changes in the skill sets and competencies required of new graduates. Evidence-based practice models, for example, require that nurses, physical therapists, and occupational therapists have the ability to identify, locate, and critically appraise research findings. The Canadian Nurses Association has stated that the competencies required by new registered nurses to meet client health needs are most effectively and economically achieved through baccalaureate nursing preparation. It is anticipated that by 2010 , the entry level for all Canadian physical therapy and occupational therapy programs will be raised from a baccalaureate program to a Master's entry-level education. Academic librarians can and should play a critical role in these new educational directives. 
Paola Durando is the liaison librarian for the School of Rehabilitation Therapy, Queen's University, Kingston, Ontario. Patricia Oakley is the Nursing Librarian for the Queen's University - St. Lawrence College Collaborative Nursing Program. Working collaboratively with faculty members within these schools, they have developed information literacy programs that enable students to acquire advanced search strategy skills, develop critical appraisal techniques, and explore the implications of literature findings for clinical practice. Teaching methods include in-class lectures, self-directed workbooks, database searching classes, graded assignments, and examination questions.

The long-term goal of these library programs is to graduate practitioners who will not only apply the information seeking and critical analysis skills they have learned in practice, but will also hopefully participate in scholarly activities and thus contribute to the evidence base in their disciplines.

\subsection{Using a blended instruction model for teaching remote health professionals: the Northern Ontario experience - Alexander Lyubechansky, Library and Information Services, Health Sciences North, Thunder Bay; and Joanne Muellenbach, Health Information Resource Centre, Northern Ontario Medical School, Thunder Bay}

\section{Introduction}

In 2000, a new, state-of-the-art regional library services project for health professionals began to develop in Northern Ontario. And since 2002, the Northern Ontario Virtual Library (NOVL) and Library and Information Services of Health Sciences North became established library services. As a result, health professionals and learners throughout Northern Ontario now have 24/7 online access to highquality biomedical databases, full-text journals and textbooks, and other electronic resources, including onsite database training and on-going user support. This has resulted in an increased demand by health professionals for database training that is customized and provided in a timely manner.

\section{Setting}

Because of the vast distances between rural and remote urban communities throughout Northern Ontario, coupled with a harsh climate, onsite library training is not always possible. Therefore, the authors have utilized a blended instruction model that incorporates various technologies with traditional teaching to overcome the barriers of distance, the wide range of learning styles, and varying degrees of comfort with information technology. The authors will discuss specific blended instruction models used, methodology, challenges, and results.

\section{Outcomes}

Using a blended instruction model has been extremely effective for our eager-to-learn, but widely dispersed, health professional population. Therefore, flexibility, a collaborative spirit between the library and technology staff, on-going evaluation, and a sense of humour are key ingredients for program success.

\section{Contributed papers concurrent sessions Session 5: Challenges to access II}

A systematic review of access to information resources

for health care professionals - Jessie McGowan, V. Robinson, L. McAuley, N. Santesso, M. Judd, K. Hannes, Pierre Pluye, Roland Grad, G. Wells, and P. Tugwell, Institute of Population Health, University of Ottawa

\section{Introduction}

Implicit in the movement towards evidence-based practice is the need for access to current best evidence. Historically, health care professionals have used a variety of information resources to provide informed, evidence-based care. Advances in information technology have made a variety of electronic and Web-based resources available. Approaches such as the provision of computer equipment and (or) Internet access have been taken to improve health care professionals' access to electronic resources. However, it is unclear if access, or attempts to provide access to the electronic information, as opposed to traditional resources, improves health outcomes for patients. Furthermore, does the type of resources that health care professionals have access to electronically impact the effect?

\section{Methods}

A systematic review of interventions to improve or provide access to electronic resources for health care practitioners is being conducted. Any objective measure of professional performance (i.e., number of times electronic resource accessed (use of resource), specialist referrals or patient outcomes (e.g., length of hospital stay)) will be included.

\section{Results}

We will report on the interventions that have been published to provide access to electronic information resources. We will attempt to determine if the type of resource or platform impact the observed effects.

\section{Conclusions}

The review will pull together a broad area of literature and will help to clarify the role that electronic information has in improving provider practice and patient care. By exploring various components of e-resources (i.e., type and platform), we hope to demonstrate important aspects in successful systems.

5.2 A vision for teaching hospital libraries: on the edge of new technology for information and service delivery - Anne Allgaier, Northern Health Authority, Prince George Regional Hospital, and Jami van Haaften, Sudbury Regional Hospital Health Sciences Library

\section{Introduction}

A hospital in Northern Ontario and one in central British Columbia develop a vision for their teaching hospital library service. What does it mean to become a teaching hospital library? Current library standards can be applied in a hospital library setting to help define the parameters of a teaching 
hospital library service. An informal national survey of teaching hospital facilities and recent library literature offers working models of how health science library services are structured in other regions.

\section{Program description}

Librarians in Sudbury, Ontario, and Prince George, British Columbia, approach the teaching hospital opportunity from different perspectives. Planned expansion of existing hospital library services is designed to meet the needs of undergraduate and graduate students, residents, and medical faculty.

\section{Outcomes}

The readiness to adequately support new clientele, while at the same time maintaining current service levels to our hospital client group, is a challenge to be met in each hospital library. The medical school development is expected to provide opportunities in both regions for the health science sector in terms of investment, recruitment, and retention. Access to information, resource sharing, virtual library services, and improved IT infrastructure are anticipated.

\section{Discussion}

Each library is working towards a service delivery model tailored to their regional needs, including a relationship with their partner in the academic health science (Faculty of Medicine) library. The premise of the medical school/teaching hospital library service is that most of the learning materials can be delivered successfully electronically. The electronic infrastructure must be able to meet the needs of this delivery model.

E-Health Library of BC, an initiative fostered by the BC Academic Health Council, representing the health authorities, universities, and colleges, and the E-Health Council of the Ontario Hospital Association indicate provincial initiatives to support electronic resources and services are planned. Hopefully the new teaching hospital libraries in Northern Ontario and Prince George, B.C. will be strong links in the National Network of Libraries for Health.

\subsection{Trying not to fall off the edge: assembling the pieces of the health information mosaic in Saskatchewan - Janet Bangma, Health Sciences Library, University of Saskatchewan, and Susan Powelson, Regina Qu'Appelle Health Region}

\section{Introduction}

At the CHLA / ABSC 2003 Conference, the presenters reported on the development of a proposal to deliver a suite of health care information resources to all health care practitioners in the province. This paper updates CHLA / ABSC members on the progress of that project.

\section{Background}

In 2002, the Saskatchewan Health Libraries Association (SHLA) was asked to develop a proposal to improve access to library resources. SHLA formed a multi-institutional task force that developed and presented a proposal to deliver health care resources for all health care practitioners, which led to the creation of the Saskatchewan Health Information Resources Partnership (SHIRP). In June 2003, the Govern- ment of Saskatchewan announced that the entire project would be funded, over three phases, and the task force began the process of implementing the plan.

\section{Outcomes}

SHIRP is tasked with delivering biomedical and full-text resources to three health regions responsible for student instruction for 2004-2005, and all health regions and health care practitioners in 2005-2006. Indicators to determine project success have been drafted along with terms of reference and a project implementation plan.

\section{Discussion}

This is a ground-breaking provincial initiative involving multiple library sectors, as well as health regions that do not currently have their own library services. SHIRP is faced with such challenges as marketing, authentication, development of a single point of access for all resources, and how to deliver training across an entire province. This paper will discuss these issues and present solutions that have been developed to date.

\section{Session 6: Challenges to access III}

\subsection{NEOS Library Consortium: a model of library cooperation and resource sharing in Alberta - Connie Clifford, Caritas Health Group, Edmonton}

\section{Introduction}

NEOS is a consortium of 19 government, health, college, and university libraries within Alberta, which cooperate to share resources, technology, collections, and people. Libraries large and small, rural and urban, academic and special - NEOS has them all.

\section{Description}

With a governance structure based on the Carver model, all member libraries have an equal voice in the operation of the Consortium. An elected executive committee, a representative board of directors, and a NEOS manager ensure that NEOS' vision, mission, goals, and objectives are met.

\section{Outcomes}

SIRSI's Unicorn integrated library system supports NEOS with a shared online catalogue and shared patron database. Cataloguing and circulation standards working groups ensure the integrity of the bibliographic records and the efficient management of circulation services. A cooperative interlibrary loan and document delivery service facilitates the sharing of collections from regions such as Grande Prairie in the north to Olds in the south.

\section{Discussion}

There are seven health libraries within NEOS, with resources and collections that are accessible and available to all patrons of NEOS libraries. These collections support academic research, patient care, rehabilitation services, mental health programs, and medical, nursing, and allied health education. Cooperative collection development ensures the provision of maximum resources at minimum cost. As library budgets shrink and the cost of information increases, library consortia such as NEOS are taking the logical next 
step to ensure that our patrons receive what they need, when they need it, and how they need it.

6.2 Equity of access: can consortia and clinical knowledge programmes truly address the imbalance? An Australian view - Marijana Bacic, Southern Health Library Network, Melbourne, Australia

\section{Introduction}

A number of clinical knowledge programmes have been implemented by several states and one territory in Australia, with the shared aim of providing an electronic library of health information to professionals within the clinical setting. These programmes supplement library initiatives that have resulted in the formation of consortia for the purchase of certain electronic resources and other cooperative ventures that aim to redistribute the costs associated with the provision of clinical information.

\section{Methods}

A review of the literature was conducted and the World Wide Web was searched. The information obtained was substantiated with data gathered from informal and structured interviews.

\section{Results and discussion}

An overview of each consortium and clinical knowledge programme is provided in terms of its development and administration. These initiatives have unequivocally improved the availability of clinical information resources for eligible institutions. However, not all health organizations have been able to benefit from these ventures. While membership of some consortia is open to all organizations involved in the health industry, eligibility for access to the clinical knowledge programmes is more strictly defined. Organizations eligible to access licenced knowledge resources provided by these programmes are often restricted to public health insti- tutions funded by the relevant state or territory government. Organizations ineligible to access resources provided by these programmes must therefore look to consortia as a means of providing access to electronic resources, if their budgets allow. While not providing the complete solution, consortia and clinical knowledge programmes provide a good foundation for addressing the inequity of access to health information.

\section{Closing keynote: Challenges to accessing health information - Dr. Gunther Eysenbach}

Gunther Eysenbach, MD (University of Freiburg - Germany), MPH (Harvard University), is currently Senior Scientist at the Centre for Global eHealth Innovation at the Toronto Research Institute - Toronto General Hospital and Division of Medical Decision Making and Health Care Research. He holds an academic appointment as Associate Professor at the Department of Health Policy, Management and Evaluation, University of Toronto.

Dr. Eysenbach founded and headed a research group on cybermedicine and eHealth at the University of Heidelberg between 1999 and 2001, where his main research interest was consumer health informatics. He came to Canada in March 2002, to join Alex Jadad in building up the Centre for Global eHealth Innovation in Toronto.

Dr. Eysenbach is the author of a German textbook for computers in medicine (which he wrote at the age of 24), editor of a loose-leaf book on computers for physicians, and founding Editor and Editor-in-Chief of the Journal of Medical Internet Research, the leading global eHealth journal. He has authored more than 90 publications, including more than 30 book chapters, as well as several pioneer studies and comments on cybermedicine, e-health, and consumer health informatics, which have been published in respected international journals such as the Journal of the American Medical Association, the British Medical Journal, and The Lancet. 
This article has been cited by:

1. GreysonDevon. 2011. Open access and health librarians in 2011. Journal of the Canadian Health Libraries Association 32:2, 45-49. [Abstract] [Full Text] [PDF] [PDF Plus] 